Int. J. Dev. Biol. 48: 103-106 (2004)

\title{
Ventral vs. dorsal chick dermal progenitor specification
}

\author{
INGRID FLINIAUX, JEAN P. VIALLET and DANIELLE DHOUAILLY* \\ Equipe Biologie de la Différenciation Epithéliale, UMR CNRS 5538, Institut Albert Bonniot, Université Joseph Fourier, Grenoble, France
}

\begin{abstract}
The dorsal and the ventral trunk integuments of the chick differ in their dermal cell lineage (originating from the somatic and somatopleural mesoderm respectively) and in the distribution of their feather fields. The dorsal macropattern has a large spinal pteryla surrounded by semi-apteria, whereas the ventral skin has a true medial apterium surrounded by the ventral pterylae. Comparison of the results of heterotopic transplantations of distal somatopleure in place of somatic mesoderm (Mauger 1972) or in place of proximal somatopleure (our data), leads to two conclusions. These are that the fate of the midventral apterium is not committed at day 2 of incubation and that the signals from the environment which specify the ventral and dorsal featherforming dermal progenitors are different. Effectively, Shh, but not Wnt -1 signalling can induce the formation of feather forming dermis from the embryonic somatopleure. Shh is not able, however, to trigger the formation of a feather forming dermis from the extra embryonic somatopleure. This brief report constitutes the first attempt, by comparing old and new preliminary results, to understand whether dermal progenitors at different sites are specified by different signalling pathways.
\end{abstract}

KEY WORDS: feather field, pteryla, heterotopic transplantation, somatopleure, signalling

\section{Introduction}

In most animals the skin appendages are not homogenously distributed but rather exhibit many variations in shape, color or density along the body axis (Jiang et al., 2004). This is particularly remarkable in the case of the avian integument. In the chick embryo, the feather primordia are grouped in fields, or pterylae, which are separated from one another by an area of low feather primordia density, the semi-apteria. The only sizeable truly featherless region is the midventral apterium, which is the extreme ventral region on each side of the midventral closure. This apterium is surrounded by the ventral pterylae and is contiguous with the amnion via the umbilical cord. The way in which the distinct pterylae, the semi apteria and the apteria are laid out is called the feather macropattern (Sengel, 1976; Mayerson and Fallon, 1985; Jung and Chuong, 1998). The information regarding the formation of the feather macropattern resides first in the mesoderm and then in the dermis, as was shown by heterotopic transplantations (Mauger, 1972) and dermal-epidermal recombinations (Dhouailly, 1973; Dhouailly, 1977). The origin of the dermis has been traced by using chick/quail chimerae. In the dorsal region of the trunk, it derives from the somite dermomyotome (Mauger, 1972). More precisely its medial compartment (Olivera-Martinez et al., 2000) gives rise to the dense dermis of the dorsal pteryla while its lateral compartment can form the dermis of surrounding semi-apteria. In case of ventral skin it is assumed that the ventral progenitors come from the somatopleural mesoderm. Thirty years ago it was proposed (Mauger, 1972) that the area close to the somites, named the proximal somatopleural mesoderm, gives rise to the feather forming dense dermis of the pterylae, while the lateral area called the distal somatopleural mesoderm forms the loose dermis of mid-ventral apterium. How is the macropattern determined at the molecular level? Until recently, the induction of pterylae formation was poorly documented. With respect to the dorsal pteryla, results from our laboratory have shown that a dorsal neural tube signal, which can be substituted by Wnt-1, causes the commitment of median dermomyotomal cells into dermal progenitors that migrate under the ectoderm to form a dense dermis (Olivera-Martinez et al., 2002; Olivera-Martinez et al., 2001; OliveraMartinez et al., 2004). Here we report some preliminary experiments and thoughts about a possible role of Sonic Hedgehog in the formation of the ventral feather fields.

\section{Signalling from the environment and specification of a feather field from the somatopleure}

At the end of the sixties, Sengel and Kieny (1967a, b) addressed the question of skin macropattern formation in chick embryo by the experimental induction of supplementary pterylae. Pieces of neural

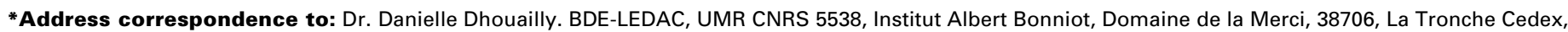
France. Fax: +33-4-76-54-94-25. e-mail: danielle.dhouailly@ujf-grenoble.fr
} 
tube, agar impregnated with brain extract, or inert foreign bodies were grafted in the presumptive territory of the midventral apterium at stages $\mathrm{HH} 13$ (2 days of incubation; Hamburger and Hamilton, agar implant. In half of those cases the surviving embryos exhibited an ectopic pteryla in the midventral apterium (reviewed by Dhouailly et al., 2004). These ectopic pterylae were circular and separated from the normal feather tracts by a semi-apterium. These results lead thus to two main conclusions. The mid-ventral apterium is not committed at early stages $\left(\mathrm{HH}_{13}\right)$ and can be induced to form feathers. Some diffusible signalling factor(s) from the neural tube can experimentally induce the dermal progenitor specification from the somatopleure. The question is, however, are the ventral and the dorsal pterylae specified by the same or different signal? one of these the same as, or able to replace, the endogenous signal(s) normally present in the environment of the somatopleure?

The competence properties of the distal somatopleural mesoderm were tested in the early seventies (Mauger, 1972). Heterotopic grafts of $\mathrm{HH} 13$ distal somatopleural mesoderm in place of the 1951). The best results were obtained with the neural tube and the Numerous signalling factors are produced by the neural tube. Is

somites of stage-matched embryos were performed (Fig. 1A). Eigth days after the graft, the embryos developed a large ectopic apterium in the dorsal pterylae (Fig. 1B). We recently performed reciprocal experiments by grafting the distal somatopleural mesoderm in place of proximal mesoderm at stage HH13 (Fig. 1C). The results (Fig. 1D) show that the ventral skin of all the grafted embryos $(n=18)$, which were analyzed 8 days later, adopted a normal ventral macropattern, i.e. complete and normal ventral pterylae on each side of the mid-ventral apterium (Fig. 1D). These results show that the environmental encountered by the somitic dermomyotome at $\mathrm{HH} 13$ is not able to induce the formation of a feather forming dermis by the distal somatopleural mesoderm. In other words, the diffusible signalling factors responsible for the commitment of the dermal progenitors might be different in case of the somatopleural mesoderm. This conclusion was confirmed by the graft of Wnt-1 producing cells (a generous gift of Dr. Nusse) in the presumptive territory of the midventral apterium. Grafts of Wnt1 cell aggregates under the presumptive territory of the midventral apterium never led to the formation of a feathered skin in the surviving embryos. The neural tube is known to produce Wnt-1 but also many other diffusible signalling factors (Capdevila et al., 1998). Among them, what could be the signalling molecules responsible for the formation of the ventral supplementary pterylae?
A
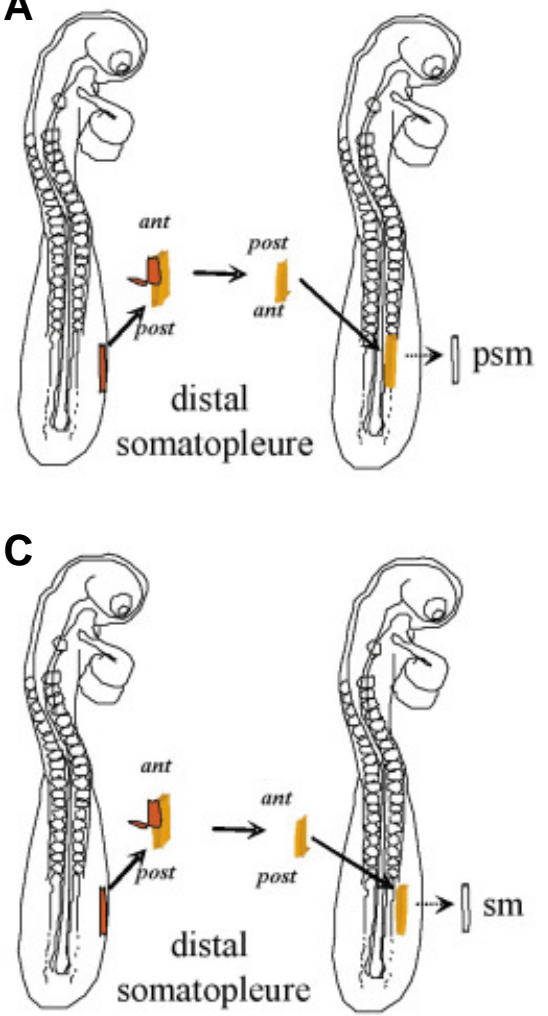
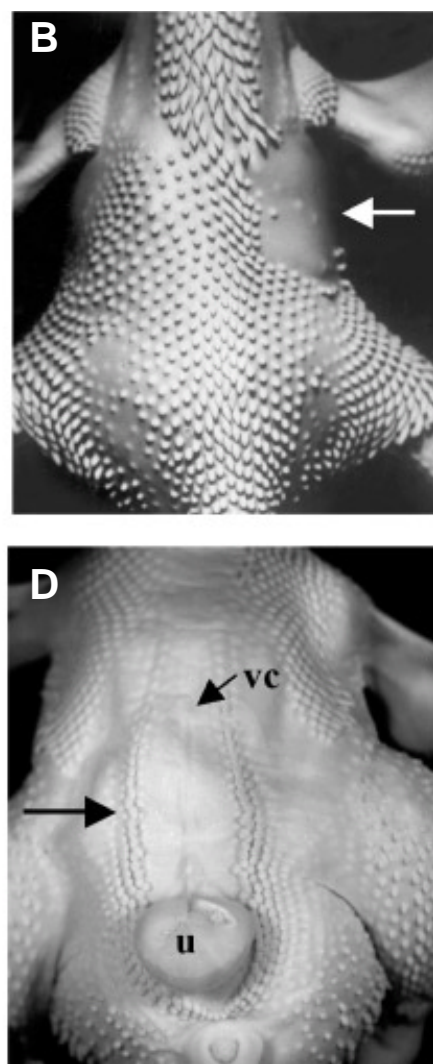

Fig. 1. The distal somatopleural mesoderm can give rise either to an apterium or a pteryla, depending on the location where it is grafted. (A) Diagram of the microsurgical procedure in chick embryo. The distal somatopleural mesoderm lafter the ectoderm is peeled off) was grafted in place of the paraxial presomitic mesoderm (psm). (B) At 11 days, a supernumerary apterium (arrow) formed across the dorsal pteryla of the grafted embryo (Mauger, 1972). (C) The distal somatopleural mesoderm was grafted in place of the proximal somatopleural mesoderm (sm). (D) At 11 days, a normal ventral feather macropattern formed. u, umbilical cord; vc, midventral closure.

\section{Shh signalling and the formation of a feather field from the somatopleure}

Part of the answer can be inferred from the pioneering work of Sengel and Kieny (1967a, b). In the case of supplementary pterylae obtained after the implantation of a foreign body, the histological analysis showed that the microsurgery leads to the fusion of the somatic and splanchnic tissues. Now, we can interpret this observation and suggest that at an early stage the splanchnopleure produces a signal which might be implicated in the commitment of the somatopleural cells as dermal progenitors in case they are brought in contact. Interestingly, recent studies show Sonic Hedgehog (Shh) expression in the embryonic endoderm at $\mathrm{HH} 13$ (Watanabe et al., 1998). Shh is also well known to be expressed in the ventral part of the neural tube (Johnson et al., 1994), and in the case of the experiments done by grafting a piece of neural tube (Sengel and Kieny, 1967a, b), either the dorsal and ventral part could have been in contact with the somatopleure. We grafted Shh producing QT6 cell aggregates (a generous gift of Dr. Duprez, Duprez et al., 1998) under the distal somatopleure at $\mathrm{HH} 13$ (Fig. $2 A)$. In one fifth of the cases $(n=9 / 45)$ the grafted embryos form a supplementary pteryla in the midventral apterium (Fig. 2B), similar to the ones previously obtained (Sengel and Kieny, 1967, a and b). By contrast the graft of QT6 control cells never resulted in the formation of a supplementary pteryla. Our results suggest that Shh could be, or could replace, the endogenous signalling that promotes the formation of the dermal progenitors from the somatopleure, i.e. the ventral pterylae. It is noteworthy that at late stages, corresponding to feather primordia formation (i.e. 10/11 days of incubation for 
A
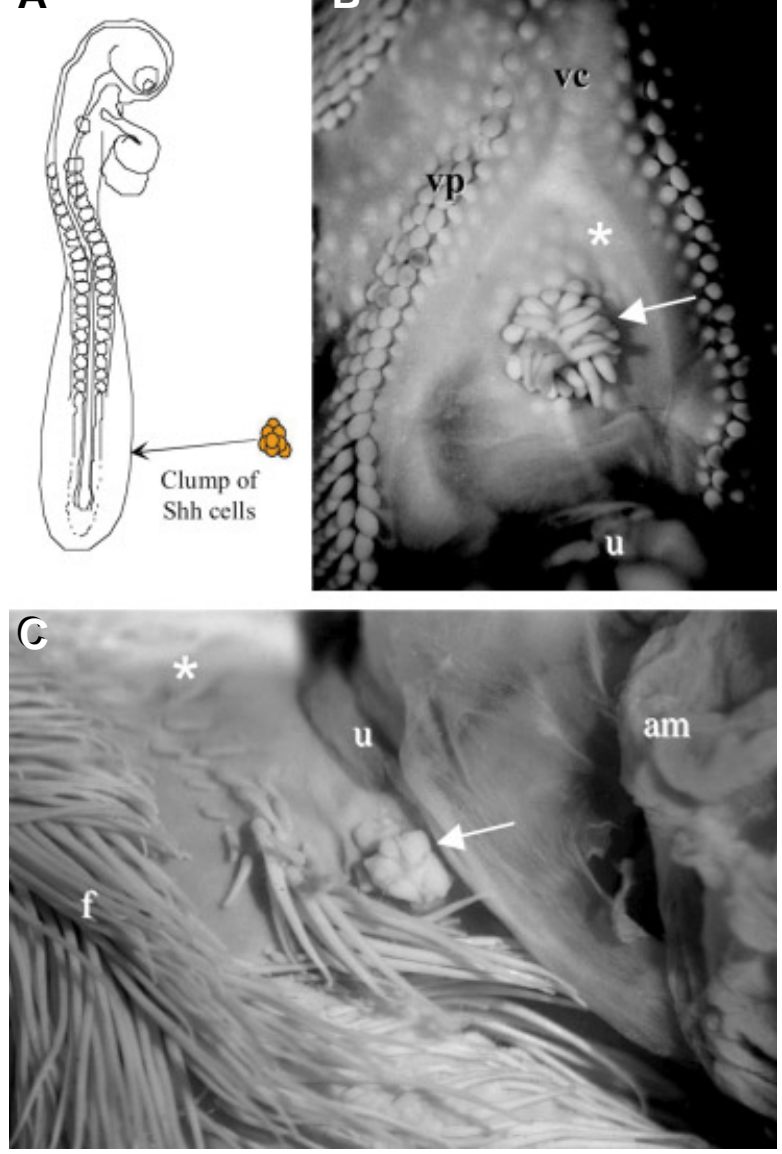

Fig. 2. Shh induction of supplementary pterylae (sp) in the embryonic but not in the extra-embryonic somatopleure. (A) Microsurgical procedure: at stage HH13, aggregates of cells engineered to produce Shh were grafted at the limit of the embryonic area, under the ectoderm. (B) When the graft was done in the presumptive territory of the midventral apterium, a supplementary pteryla was obtained after 8 days. (C) When the graft was performed in the presumptive territory of the umbilical cord and examined 13 days later only minute protrusions were formed (arrow). am, amios; $f$, feather; $u$, umbilical cord; vc, midventral closure; vp, ventral pteryla.

ventral skin, or 6.5-7 days for dorsal skin), ectopic Shh can induce supplementary feather formation (Ting-Berreth and Chuong, 1996; Jung et al. 1998; Morgan et al. 1998). In case of ventral skin, the ectopic feather primordia are localized on the midline of the ventral closure, a region which can normally produce a few short feathers in $9 \%$ of untreated embryos (Sengel etal., 1969). It is well know that Shh can enhance the feather outgrowth at the stage of feather initiation (Jung et al. 1998; Prin and Dhouailly 2004). Thus it is important to distinguish between two different effects of Shh: its enhancing effect on feather formation at a relative late stage (10/ 11 days for ventral skin) and its much earlier experimental effect (between 2 and 7 days) on the initiation of a novel feather field (our results).

As the extra-embryonic somatopleure is autonomously also able to form ectopic pterylae (Dhouailly, 1978; for a review see Dhouailly, 2004), we grafted in a second series of experiments Shh(-) aggregates under the extra-embryonic ectoderm at stage
HH13. Thirteen days afterwards no pterylae formed and only minute protrusions from the umbilical cord were observed in a few cases ( $n=5 / 36)$ (Fig. 2D). These results lead to the conclusion that Shh is not sufficient to trigger the formation of a feather forming dermis from the extra embryonic somatopleure.

\section{Concluding remarks}

Revisiting the problem of ventral versus dorsal chick skin formation should give us the opportunity to analyze whether or not dermal progenitors in different regions might be specified by different signalling pathways. The ventral and dorsal dermal progenitors appear thus to differ not only in their cell lineage, but also in their ability to respond to different environmental inductions. Shh signalling can experimentally and at an early stage induce feather forming dermis from the embryonic midventral region, but not from the extra-embryonic somatopleure. Further studies currently in progress should show what is (are) the endogenous signalling factor(s) which specify(ies) the ventral feather-forming dermal progenitors and consequently the ventral macropattern.

\section{Acknowledgments}

The authors would like to thank Dr. D. Pearton for critical reading of the manuscript and to Mrs. B. Peyrusse for iconography.

\section{References}

CAPDEVILA J., TABIN C. and JOHNSON R.L. (1998) Control of dorsoventral somite patterning by Wnt-1 and beta-catenin. Dev Biol. 193, 182-94.

DHOUAILLY, D. (1973). Dermo-epidermal interactions between birds and mammals: differentiation of cutaneous appendages. J. Embryol Exp Morphol. 30, 587-603.

DHOUAILLY, D. (1977). Dermo-epidermal interactions during morphogenesis of cutaneous appendages in amniotes. In Frontier Matrix Biology (ed. L. Robert), 4.Creteil.

DHOUAILLY, D. (1978). Feather-forming capacities of the avian extra-embryonic somatopleure. J Embryo Exp Morphol. 43, 279-87.

DHOUAILLY, D., OLIVERA-MARTINEZ, I., FLINIAUX, I., MISSIER, S., VIALLET, J.P and THÉLU, J. (2004). Skin field formation: morphogenetic events. Int. J. Dev. Biol. 48: 85-91.

DUPREZ, D., FOURNIER-THIBAULT, C. and LE DOUARIN, N. (1998). Sonic Hedgehog induces proliferation of committed skeletal muscle cells in the chick limb. Development. 125, 495-505.

HAMBURGER, V. and HAMILMTON, H. L. (1951). A series of normal stages in the development of the chick embryo. JMorphol. 88, 49-92.

JIANG, T.X., WIDELITZ, R.B., SHEN W.M.,WILL, P., WU, D.Y., LIN, C.M., JUNG, H.S. and CHUONG, C.M. (2004). Integument pattern formation involves genetic and epigenetic controls: feather arrays simulated by digital hormones. Int. J. Dev. Biol. 48: 117-136.

JOHNSON, R.L., LAUFER, E., RIDDLE, R.D. and TABIN, C. (1994) Ectopic expression of Sonic hedgehog alters dorsal-ventral patterning of somites. Cell. 79, 1165-73.

JUNG, H.S. and CHUONG, C. M. (1998). Periodic pattern formation of the feathers. In Molecular basis of epithelial appendage morphogenesis (ed. C. H. Chuong), Unit Vol.1, pp. 359-369. Georgetown, Texas, USA: R. G. Landes Company, Molecular Biology Intelligence.

JUNG, H.S., FRANCIS-WEST, P.H., WIDELITZ, R.B., JIANG, T.X., TING-BERRETH, S., TICKLE, C., WOLPERT, L. and CHUONG, C.M. (1998). Local inhibitory action of BMPs and their relationships with activators in feather formation: implications for periodic patterning. Dev. Biol. 196: 11-23.

MAUGER, A. (1972). The role of somitic mesoderm in the development of dorsal plumage in chick embryos. I. Origin, regulative capacity and determination of the plumage-forming mesoderm. J Embryo Exp Morphol. 28, 313-41. 
MAYERSON, P. L. and FALLON, J. F. (1985). The spatial pattern and temporal sequence in which feather germs arise in the white Leghorn chick embryo. Dev Biol. 109, 259-67.

MORGAN, B. A., ORKIN, R. W., NORAMLY, S. and PEREZ, A. (1998). Stagespecific effects of sonic hedgehog expression in the epidermis. Dev. Biol. 201, 1-12.

OLIVERA-MARTINEZ, I., COLTEY, M., DHOUAILLY, D. and POURQUIÉ, O. (2000). Mediolateral somitic origin of ribs and dermis determined by quail-chick chimeras. Development. 127, 4611-4617.

OLIVERA-MARTINEZ, I., THELU, J., TEILLET, M. A. and DHOUAILLY, D. (2001). Dorsal dermis development depends on signal from the dorsal neural tube, which can be substituted by Wnt-1. Mech Dev. 100, 233-44.

OLIVERA-MARTINEZ, I., MISSIER, S., FRABOULET, S., THELU, J. and DHOUAILLY, D. (2002). Differential regulation of the chick dorsal thoracic dermal progenitors from the medial dermomyotome. Development. 129, 476372.

OLIVERA-MARTINEZ, I., THELU, J. and DHOUAILLY, D. (2004). Molecular mechanisms controlling dorsal dermis generation from the somitic dermomyotome. Int. J. Dev. Biol. 48: 93-101.
PRIN, F. and DHOUAILLY, D. (2004). How and when the regional competence of chick epidermis is established: feathers $v s$. scutate and reticulate scales, a problem en route to a solution. Int. J. Dev. Biol. 48: 137-148.

SENGEL, P. (1976). Morphogenesis of skin. In Developmental and Cell Biology series (ed. M. Abercrombie, D. R. Newth and J. G. Torrey), pp. 1-269. Cambridge University Press.

SENGEL, P., DHOUAILLY, D. and KIENY, M. (1969). Aptitude of the skin constituents of the mid-ventral apeterium of the chicken for forming feathers. Dev Biol. 19, 436-46.

SENGEL, P. and KIENY, M. (1967a). Production of a supplementary pteryla in the chick embryo. I. Morphologic study. Arch Anat Microsc Morphol Exp. 56, 11-29.

SENGEL, P. and KIENY, M. (1967b). Production of an additional feather tract in the chick embryo. II. Experimental analysis. Dev Biol. 16, 532-63.

TING-BERRETH, S. A. and CHUONG, C. M. (1996). Sonic Hedgehog in feather morphogenesis: induction of mesenchymal condensation and association with cell death. Dev Dyn. 207, 157-70.

WATANABE, Y., DUPREZ D., MONSORO-BURQ A. H., VINCENT C. and LE DOUARIN NM. (1998). Two domains in vertebral development: antagonistic regulation by SHH and BMP4 proteins. Development 125, 2631-9. 